"ground moraine." I lay no claim to having invented it; I find, indeed, that it was used by Sir Andrew Ramsay at least as far back as the publication of his "Physical Geology of Great Britain." Perhaps I may be permitted to commend it to Mr. Gardner as a useful English equivalent for the French phrase so much in use.

Jas. DerHay.

\title{
PACKING OF SAND GRAINS AS COMPARED WITH ROUND SHOT.
}

SIR,-I am indebted to your correspondent, Prof. A. Harker, for his suggestion and for recalling my attention to this subject (p. 192). No doubt, as he states, round shot could be so packed as to leave much less interstitial space than what would result from my hypothetical arrangement. But even if perfect spheres of absolutely the same size could be obtained and friction eliminated, they could not fall together naturally in perfect "pyramidal order," i.e. each shot having points of contact with twelve others; because their arrangement is conditioned by the packing which takes place against the sides of the vessel. If on the other hand they were unconfined as in a heap, their arrangement would be one of disorder.

To thoroughly test what practically happens, I filled a rain-gauge measurer up to the mark 30 with No. 4 shot carefnlly put in layers, and sbaken to get them as close together as possible. A second raingauge measurer being filled also up to 30 with water, I poured sufficient from it among the shot to fill up the insterstices. I found that 18 remained in the gauge, leaving 12 among the shot, a relation of 4 to $6 .^{1}$ This shows somewhat less interstitial space than my hypothetical arrangement assumed, but considerably more than the "pyramidal order" arrangement. It is plain to see through the glass that the number of points of contact of the shots vary, and leave variable open spaces in places. This shows that minute differences in size, imperfection of spheroidal shape, and to a large extent the packing against the sides of the vessel and friction, are disturbing elements. Some time ago for the purposes of a paper on sandstones I repeated the experiment mentioned in "Miniature Domes in Sand" on a larger scale, and in a somewhat different way, taking great care to shake the sand well together in layers, as I afterwards did with the shot. Curiously enough, the result was within a third decimal place of that I now give for the shot. The grains are mostly well-rounded, but some of them are angular, and the sizes of the grains vary considerably. It is surprising how the sand will keep on packing closer and closer by shaking, whereas the shot is affected to the extent of a reduction of its bulk by only $\frac{1}{30}$. The question is one of considerable practical interest. I find if a trench for a sewer intersects another trench which may have been filled up for years, and all in apparently homogeneous siliceous sand, the filling in of the old trench discovers itself by falling into the new one, while the sides cut in the "growing" sand remain vertical. Thus it appears that percolation of rain assisted by gravity is slowly moving and packing the grains of sand until they reach the point of maximum consolidation. It is in fact a natural building operation which may be likened to the fitting together of rubble, shot from a cart, to form a wall. Pouring water on filled-up sand will consolidate it, and I am in the habit of having this done where a floor has to be made on filled-up sand. It is remarkable how solid sand becomes in time left only to natural influences. I have frequently built large houses on sandhills without failure of foundation.
Park Corner, Bunndelisands,
T. Mellard Reade. April 5th, 1884.

${ }^{1}$ If this experiment were repeated with larger vessels, the proportions might differ more. 